\title{
LEITE CLANDESTINO: A INFORMALIDADE ORIENTADA PELA DEMANDA - UM DIAGNÓSTICO DA PRODUÇÃO E COMERCIALIZAÇÃO EM ITAQUI/RIO GRANDE DO SUL ${ }^{1}$
}

\author{
Janaína Balk Brandão² \\ Raquel Breitenbach ${ }^{3}$ \\ Vinicius Santos Dias ${ }^{4}$ \\ Fabiele Batiste da Silva ${ }^{5}$
}

\begin{abstract}
Resumo
O leite é um dos principais alimentos dos humanos além de contribuir na geração de renda e emprego. Porém, muitas fraudes vêm sendo descobertas recentemente nesse mercado, bem como persiste o mercado informal do produto. Nesse contexto, o presente estudo tem como objetivo realizar uma caracterização sócio-econômica dos estabelecimentos que produzem e comercializam leite no mercado informal de Itaqui/RS, com o propósito de identificar as motivações que fazem com que os produtores atuem na informalidade. Esta pesquisa é um Estudo de Caso, em que realizou-se entrevista a vinte produtores e ao técnico da empresa de assistência técnica, além de observação direta e coleta de dados secundários. Os resultados evidenciam que os produtores estão localizados na periferia da área urbana do município, utilizam mão de obra familiar e atuam no mercado informal em função de suas características econômicas, especialmente a baixa escala de produção, demanda garantida e o valor pago pelos clientes.
\end{abstract}

Palavras-chave: Instrução normativa $n^{\circ} 51$, mercado informal, produtores.

\section{CLANDESTINE MILK: A DRIVEN BY DEMAND INFORMALITY - A DIAGNOSIS OF PRODUCTION AND MARKETING IN ITAQUI/RIO GRANDE DO SUL}

\begin{abstract}
Milk is one of the main foods of humans besides contributing in a remarkable way in the generation of income and employment. However, many frauds have been discovered recently. Added to this, it is known that a portion of the milk consumed nowadays is native from the informal market. In this context, the present study aims to perform a socio-economic characterization of the establishments that produce milk in Itaqui / RS, seeking to understand the motivations that make with the producers act informally. This research is a case study. For this purpose, it was done an interview with twenty producers and with the technician of the company from the technical assistance, direct observation and data collection records of state agencies.

\footnotetext{
${ }^{1}$ Pesquisa utilizou recursos Edital No 03/2013 - Programa de Bolsas de Iniciação à Pesquisa (PBIP) Unipampa/Campus Itaqui.

${ }^{2}$ Graduada em Agronomia (UFSM). Mestrado e Doutorado em Extensão Rural (UFSM). Professora Adjunta Unipampa em exercício provisório na UFSM. E-mail: janainabalkbrandao@hotmail.com

${ }_{3}$ Graduada em Desenvolvimento Rural (UERGS). Mestrado e Doutorado em Extensão Rural (UFSM).

Professora IFRS - Sertão. E-mail: raquel.breitenbach@sertao.ifrs.edu.br

${ }^{4}$ Graduado em Agronomia (Unipampa).E-mail:viniciusdias_agro@yahoo.com.br

${ }^{5}$ Graduado em Agronomia (Unipampa). E-mail: fabielebastide@hotmail.com
} 
The results showed that producers are located on the outskirts of the urban areas, they use family labor and act in the informal market because of its economic characteristics, especially the low production scale, guaranteed demand and the value paid by customers.

Keywords: Normative instruction No. 51, informal market, producers.

\section{INTRODUÇÃO}

O leite é um dos principais alimentos dos humanos, sendo que através dessa matéria-prima produzem-se centenas de produtos, além de contribuir de forma marcante na geração de renda e emprego no meio rural. Porém, muitas fraudes vêm sendo denunciadas e descobertas recentemente, de modo especial a partir de 2013. A adição de substâncias estranhas à composição normal do leite pode ocorrer desde a fonte de produção até a fase de comercialização, alterando sua qualidade nutritiva. É nesse contexto que Santucci (2013) alerta que no ano de 2013, cerca de 600 mil litros de leite foram detectados com indícios de fraudes no Rio grande do Sul.

A cadeia produtiva do leite é um setor importante para a economia brasileira. Conforme dados da Barbosa (2003) o leite é um dos seis primeiros produtos mais importantes da agropecuária brasileira, estando a frente de produtos como café beneficiado e o arroz. O Brasil ocupava, em 2013, a sexta colocação em produção de leite, chegando a 22.595.267,3 toneladas (FAOSTAT, 2013). O Rio Grande do Sul ocupa posição de destaque em quantidade produzida, ocupando a segunda posição, bem como em produtividade, sendo esta cerca de 2700 litros/vaca/ano, estando a frente dos principais estados produtores, que são Minas Gerais, Santa Catarina, Paraná, Goiás e São Paulo (IBGE, 2012). A posição de destaque também se observa na taxa de crescimento que foi a segunda maior no período de 2007 a 2012, sendo de 5,8\%, abaixo apenas de Paraná com 6,8\%.

A produção brasileira de leite cresceu cerca de 4,5\% saltando de 30,7 bilhões de litros em 2010 para 32,1 bilhões de litros em 2011, o que colocou o Brasil na terceira posição no ranking dos maiores produtores de leite do mundo, ficando atrás apenas dos Estados Unidos e Índia (IBGE, 2012). O Rio Grande do Sul representa cerca de $10,6 \%$ da produção nacional, em que $90.5 \%$ dos municípios gaúchos, ou seja, 449 são produtores de leite (SINDILAT/RS, 2012).

No município de Itaqui, localizado na região Fronteira Oeste do Rio Grande do Sul a produção das lavouras, principalmente de arroz, representa cerca de $80 \%$ da economia agrícola, ficando os outros $20 \%$ a cargo da pecuária e de outras atividades (IBGE, 2012). A produção de leite deste município é em torno de 2.859 mil litros/dia (IBGE, 2012) totalizando uma participação de 0,1 \% para a produção do estado. Apesar da produção pouco expressiva, têm famílias que vivem da renda gerada pela produção de leite, tendo, portanto, importância para aqueles que estão envolvidos diretamente com a atividade.

Ressalta-se ainda, que a cadeia produtiva do leite apresenta um mercado em que está presente de forma expressiva a informalidade. Em 2010, a Scot Consultoria estimou que a produção de leite no país tenha sido de 30,8 bilhões de litros, correspondendo a $30,8 \%$ da produção de leite na informalidade. No Rio Grande do Sul, por exemplo, a produção de leite em 2009 foi de 3.400 .179 mil litros, segundo a Pesquisa Pecuária Municipal do IBGE. Desse total, 81\% foram provenientes de estabelecimentos (laticínios) com algum tipo de inspeção e a informalidade estimada foi de $19 \%$. No Brasil ainda é comum o comércio do "leite 
informal" também chamado de "leite clandestino". Wilkinson e Mior (1999) fizeram uma importante distinção entre setor informal e ilegal, destacando que o primeiro tem como característica o fato de seus produtos não serem proibidos, ou seja, são basicamente atividade com processos de produção fora de padrões de regulação vigentes, especialmente as normas reguladoras do Estado.

De acordo com Nero, Maziero e Bezerra (2003), o hábito de consumir leite cru, ou informal, por uma parcela considerável da população, está diretamente relacionado com conceitos previamente formados de que este produto possui boa qualidade, além de desconhecimento dos riscos à saúde que esse pode oferecer. Destaca-se ainda, que se consideradas as reflexões de Wilkinson e Mior (1999), existem estratégias alternativas de reprodução da agricultura familiar, apontando que muitas vezes este setor identifica oportunidades de mercado distintas, como é o caso do mercado informal. Quando a estratificação se refere a pequenas unidades de produção familiares, como é o caso das analisadas nessa pesquisa, a informalidade pode ser a estratégia mais viável, ou a única ação viável para a sobrevivência dos estabelecimentos.

O comércio de leite cru é proibido no Brasil desde a década de 1950 pela Lei $n^{\circ}$ 1.283, de 18/12/1950, e pelo Decreto $n^{\circ} 30.691$, de 29/03/1952 (BRASIL, 1997). Entretanto, a comercialização de leite clandestino no Brasil teve crescimento a partir do início da década de 1990 uma vez que, durante esse período, a cadeia produtiva do leite passou por um profundo processo de transformação, tanto em termos estruturais como institucionais, exigindo diversos ajustes e adaptações para se aproximar do nível de qualidade, volume e regularidade que o varejo e as empresas laticinistas passaram a demandar (OLIVAL; SPEXOTO, 2004). Prova disso é o estabelecimento da Normativa no 51 desde 2002, por meio da qual o Ministério da Agricultura, Pecuária e Abastecimento (MAPA) regulamenta a produção, identidade, qualidade, coleta e transporte do leite $A, B, C$, pasteurizado e cru refrigerado.

Carvalho (2010) também alerta que os avanços na cadeia láctea como um todo foram grandes nos últimos anos, entre os quais se destaca: pagamento por qualidade, implementação de legislação mais dura em termos de produção com qualidade, coleta a granel, distribuição e consumo, estrutura de fornecedores e internalização, fatores estes que mudaram a forma de produzir e comercializar leite no país. Para os pequenos produtores as mudanças são revestidas de distintos impactos, pois nem todos conseguem acompanhar a demanda da indústria e dos consumidores no que se refere às melhorias na questão da gestão da produção, qualidade e sanidade do produto final.

Apesar desta reestruturação da cadeia láctea, muitos produtores, normalmente de pequeno porte, não conseguem acompanhar estes avanços, o que os leva a atuar na informalidade, como mostra Farina (2000) quando ressalva que na cadeia produtiva do leite no Brasil - apesar das recentes mudanças ocorridas (reestruturação industrial, aumento do consumo, aumento das exportações, mudanças nas exigências legais, etc.) - persistem os problemas da informalidade. A fiscalização ainda é falha e a informalidade do leite no país é elevada.

Não obstante todos os problemas que podem ocorrer com o leite inspecionado, sabe-se que o comércio informal de leite pode ser uma grande ameaça à saúde pública visto que, segundo a Organização Mundial de Saúde (OMS), dezesseis doenças bacterianas e sete viróticas são veiculadas pelo produto, dentre elas a tuberculose, a brucelose e gastroenterites, sendo esta uma das responsáveis pela baixa qualidade do leite (BADINI; NADER; AMARAL, 1997). A informalidade ainda pode ocasionar problemas de ordem econômica, a exemplo da não 
arrecadação de tributos pelo governo e concorrência desleal com empresas legalizadas (BÁNKUTI, SCHIAVI, SOUZA FILHO 2005).

Diante das transformações ocorridas na atividade leiteira, e da importância do leite na alimentação humana o presente estudo tem como objetivo geral realizar uma caracterização sócio-econômica dos estabelecimentos que produzem leite em Itaqui/RS e não estão inseridos nos padrões exigidos pela legislação. Além disso, busca-se quantificar os produtores de leite que estão na informalidade, verificando quais as suas formas de produção e tipos de comercialização utilizados, identificando o nível de conhecimento e informação, produtividade do rebanho e relacionamento do produtor com o consumidor.

\section{REVISÃO DE LITERATURA}

\subsection{A produção de leite}

O Agronegócio do leite e seus derivados desempenham um papel de suma importância no suprimento de alimentos e na geração de emprego e renda para a população mundial. A produção primária de leite está disseminada em todo o território mundial, sendo suas formas produtivas muito díspares, caracterizando-se por realidades muito distintas quanto à produtividade e custos (CARVALHO, 2008).

Segundo dados da FAO (2010), a produção mundial de leite no ano de 2010 foi de 599,61 milhões de toneladas. As maiores participações relativas na produção mundial são dos Estados Unidos da América, com 14,6 \%, logo após Índia, com $8,4 \%$ do total, seguido da China com uma participação de $6 \%$ da produção mundial. A produção brasileira em 2010 foi equivalente 5,3\% do total, ocupando o quinto lugar na posição no ranking dos maiores produtores de leite do mundo. Alguns países tradicionais exportadores de leite, como Austrália, Nova Zelândia e Argentina, apresentaram uma participação relativa em torno de 2,8 a 1,5 \%. (EMBRAPA GADO DE LEITE, 2012)

Nos últimos anos, a produção mundial de leite vinha apresentando uma trajetória de expansão apenas discreta. Nos anos entre 1990 a 2000 cresceu apenas $6,8 \%$, muito abaixo das taxas de crescimento verificadas entre 1980 e 1990 (16,5\%) e entre 1970 e 1980 (18,8\%). Mais recentemente, a produção mundial voltou a se expandir de maneira mais significativa; entre 2000 e 2005 o crescimento foi de $8,6 \%$. Esse crescimento da produção mundial é explicado especialmente pelo comportamento da produção de alguns poucos países, que têm compensado com alguma folga o pequeno crescimento, a queda ou a estabilidade na produção de alguns dos principais produtores mundiais. Está havendo uma clara e constante mudança na geografia da produção mundial (SANTOS; MARCONDES; CORDEIRO, 2006).

Pinha, Travassos e Carvalho (2010) analisam a produção mundial de leite no período de 1992 a 2008, no qual constatam um crescimento anual médio de $1,4 \%$, saindo de 460,7 milhões de toneladas em 1992, para 578,5 milhões de toneladas em 2008. Este incremento na produção mundial permitiu o aumento do consumo de produtos láteos, não somente para o leite fluido, mas principalmente para derivados, como queijo e manteiga (SANTINI; PEDRA; PIGATTO, 2009). Carvalho (2008) aponta que as regiões que aumentaram a produção de leite são aquelas que também registraram maior aumento de consumo de produtos lácteos, associando esse incremento à intensificação da urbanização e ao incremento da renda, e nas mesmas regiões é possível um crescimento futuro na produção de leite.

O Brasil é tradicionalmente um grande produtor de leite. A atividade que começou com características extrativistas, ocupa posição de destaque no cenário 
econômico nacional, sendo um dos principais negócios agrícolas do Brasil, pois está presente em quase todos os municípios brasileiros. Dos 5.564 municípios existentes no País, apenas 67 não produzem leite e dos 100 municípios que mais produzem leite, 53 tem o leite como a principal atividade econômica (IBGE, 2012).

A pecuária leiteira é praticada em todas as regiões, sendo representada por mais de um milhão de propriedades rurais e gerando, somente no segmento primário, mais de três milhões de empregos diretos (SCALDO, 2005). De acordo com EMBRAPA (2010) o Brasil tem continuamente ampliado sua produção a taxas anuais de $4,9 \%$ entre 2000 e 2008 . No entanto, a produção leiteira no País ainda é caracterizada por grande heterogeneidade, tanto nas técnicas de produção quanto no rebanho e tipo de produtores, pois $80 \%$ das propriedades de leite do Brasil são pequenas e respondem por apenas $27 \%$ do volume produzido, enquanto que $20 \%$ das propriedades são classificados como grandes e respondem por $73 \%$ da produção. Para as pequenas, a média da produção é de apenas 13,61 litros/estabelecimento/dia.

De acordo Maia et al (2013), há décadas a maior parte do leite produzido no país é oriunda da Região Sudeste. Entretanto, a região que era responsável por mais da metade da produção nacional, em 1974, vem perdendo participação relativa e, em 2011, passou a responder por, aproximadamente, um terço do leite brasileiro. O Nordeste manteve sua contribuição estável (em torno de $13 \%$ da produção), enquanto as regiões Norte, Centro-Oeste e, sobretudo, a Região Sul ganharam participação. Esta última apresentou um salto de produção na década de 2000 , chegando, em 2011, a 32\% da produção nacional (MAIA et al, 2013), com base em dados da Pesquisa Pecuária Municipal.

A competitividade do Brasil nesse mercado é vantajosa devido ao econômico sistema de produção, que é, em sua maior parte, a pasto. Além disso, há possibilidade de crescimento horizontal da produção, com aumento da área de rebanho de gado leiteiro, e vertical, com melhoramento genético, nutricional e de manejo (LEITE, 2008).

\subsubsection{Produção leiteira: aspectos normativos}

O leite é um alimento de grande importância nutricional para o homem em todas as fases de sua vida, porém, para tenha características nutricionais e não prejudique a saúde do consumidor é necessário que seja um produto de qualidade (PORTZ, 2011).

O primeiro marco de organização da produção leiteira data de 29 de março de 1952, quando Getúlio Vargas assinou o Decreto 30.691, aprovando o Regulamento de Inspeção Industrial e Sanitária de Produtos de Origem Animal (Riispoa), aplicado nos estabelecimentos que realizam comércio interestadual ou internacional, tornando obrigatória à pasteurização, bem como a inspeção e o carimbo do Serviço de Inspeção Federal (SIF). A partir de 1952 foi publicado outro Decreto que introduziu a classificação dos leites em tipos $A, B$ e $C$ em função das condições sanitárias de sua obtenção, processamento, comercialização, durabilidade e contagem microbiana.

O Riispoa foi parcialmente modificado algumas vezes desde sua publicação, e uma das mais importantes modificações foi introduzida em função da adesão do Brasil ao Mercado Comum do Sul (Mercosul). Em 18 setembro de 2002, foi instituída a Instrução Normativa 51 (IN 51), que aprova os regulamentos técnicos de produção, identidade e qualidade de Leite tipo A,B,C, pasteurizado e do Leite Cru Refrigerado, bem como a regulamento técnico da coleta de leite cru refrigerado e seu granel (BRASIL, 2002). Esta normativa tem como objetivo a melhoria da 
qualidade do leite brasileiro, por meio do Programa Nacional de Melhoria da Qualidade de leite, estabelecendo a padronização dos parâmetros físico-químicos e microbiológicos dos diversos tipos de leite, bem como das características estruturais necessárias para sua produção e transporte, obrigando os estabelecimentos com Serviço de Inspeção Federal (SIF) a implantarem a Análise de Perigo e Pontos Críticos de Controle - APPCC e as Boas Práticas de Fabricação - BPF (PERIN, FERREIRA; TALAMINI, 2009).

Em virtude da dificuldade do produtor de se adequar aos novos padrões, a Instrução Normativa 51 foi substituída pela Instrução Normativa 62, de 29 e dezembro de 2011 (IN 62). Essa instrução previa a extinção dos leites B e C, em virtude da baixa produção de leite $B$, passando ambos a ser identificados apenas como leite cru refrigerado (GUERRA, 2012). Posteriormente, foram ampliados os prazos para adequação dos produtores.

\subsubsection{Informalidade na Produção Leiteira}

Embora o crescimento da produção possa ter aumentado e a legislação vigente, de certa forma, incentive a produção, o mercado informal ainda possui grande relevância. Nero, Maziero e Bezerra (2003) afirmam que apesar de ilegal, a venda de leite cru representa uma importante atividade comercial uma vez que, embora muitos desconheçam os riscos, a demanda também é grande.

O consumo de leite informal está associado a hábitos culturais, como "produto artesanal" ser fresco, mais forte, saudável, isento de substâncias químicas (GOMES, 2000). Porém, sabe-se que a qualidade do alimento está diretamente relacionado com o status sanitário do produto, desde a matéria-prima até chegar ao consumidor (SILVA, JUNQUEIRA; SILVEIRA, 2000).

É possível lançar a hipótese de que as recentes comprovações de fraude na indústria formal de leite geraram um período de insegurança no consumidor no que se refere ao leite formal. Estes podem estar associando leite formal a leite adulterado, visualizando o leite informal como um leite puro e saudável. Destaca-se que os riscos de consumo podem ocorrer nas duas esferas, tanto quando adquirido leite formal adulterado, quanto no caso do leite sem fiscalização e comprovação de qualidade. Ressalta-se que se trata de uma hipótese de uma possível migração de consumo do leite formal para o informal após as descobertas de fraudes, já que não foram identificadas publicações de pesquisas após esses acontecimentos que indicassem/comprovassem tal hipótese.

De acordo com Santos et al (2002) e Vilela, Leite e Resende (2002) a produção de leite informal é muito resistente a crise por ter um mercado consumidor fiel, porém esse mercado tem dificuldade de desenvolver. Para os produtores que realizam esta prática, o desconhecimento técnico e a falta de recursos financeiros para o investimento no estabelecimento, além da ausência de fiscalização são fatores que permitem $100 \%$ do aproveitamento dos produtos que seriam passíveis de condenação (GERMANO, 2003).

$\mathrm{O}$ consumo de leite e derivados informais causam inúmeros prejuízos à saúde da população, mas esses dados são inconstantes e, na maioria das vezes, não divulgados. O conhecimento dos principais patógenos existente no leite cru, desde as etapas iniciais de produção, é de extrema importância para a Saúde Pública, uma vez que a partir desses dados seria possível a criação de políticas de controle de possíveis enfermidades causadas por esses agentes (SCALCO, 2005).

Segundo dados do IBGE (2010), entre os anos de 1990 e 1999, a produção de leite informal no Brasil aumentou 150\%, embora havendo o crescimento da produção formal. Embora os governos (federal, estaduais e municipais) tenham a 
ciência de que é preciso fazer algo para prevenir e eliminar o comércio informal do leite e dos derivados lácteos, pouco foi feito durante os últimos anos. Santos e Fonseca (2002) e Vilela, Leite e Resende (2002) citam a demora das instituições públicas atuarem no sentido de trazer esses pequenos produtores para o mercado formal.

A relação leite formal e leite informal está diminuindo gradativamente, passando de $57 \%$ e $43 \%$ respectivamente, em 1997 , para $70 \%$ e $30 \%$ respectivamente em 2007. Apesar desta evolução, isto não significa necessariamente que as políticas de combate à informalidade estão cumprindo seu papel plenamente. Analisando pormenorizadamente os dados, nota-se que a redução percentual da informalidade é creditada a elevação absoluta mais acentuada da produção formal do que a informal que também apresentou leve aumento no período de 1997 a 2008 (SIMÕES; OLIVEIRA, 2010).

A produção brasileira de leite sob inspeção oficial aumentou $9,88 \%$, de janeiro a dezembro de 2007, em comparação ao mesmo período de 2006, de acordo com o Índice de Captação de Leite, do Centro de Estudos Avançados em Economia Aplicada (CEPEA), sendo que nos últimos dez anos a meta de aumento registrada foi de $6,6 \%$ (ZANELA, RIBEIRO; FISCHER, 2009).

\section{INFORMALIDADE DENTRO DO SISTEMA AGROINDUSTRIAL DO LEITE}

De acordo com Bánkuti (2009) um Sistema Agroindustrial (SAI) do leite padrão no Brasil é formado por alguns agentes principais, entre estes estão: (a) produtores rurais; (b) indústria de laticínios; (c) varejo e (d) consumidores. Nesse sistema, os agentes estão condicionados a um conjunto de Leis (regras formais) entre as quais se destacam: Instrução Normativa $N^{\circ} 51$; Sistemas de Inspeção Sanitária; Leis relativas à tributação entre outras. O produtor rural, por exemplo, deve resfriar o leite logo após a ordenha e entregá-lo para um laticínio. Na indústria, o leite deve passar por um conjunto de análises e receber tratamento térmico adequado (ex.: pasteurização ou ultra-pasteurização), para em seguida ser embalado e distribuído ao varejo; este por sua vez, deve disponibilizar o produto ao consumidor final de maneira adequada, respeitando, por exemplo, o código de defesa do consumidor.

Embora este sistema fosse o ideal na cadeia produtiva do leite, no Brasil o mecanismo de cumprimento destas Leis é pouco eficiente, além disso, há uma série de incentivos para que os agentes operem em um mercado paralelo, aqui denominado de subsistema informal ou clandestino (BÁNKUTI, 2009). Um exemplo recorrente é observado na venda direta de leite e queijo (mercado informal) pelo produtor rural ao consumidor. Neste subsistema, as etapas que seriam realizadas pela indústria e varejo não são cumpridas pelo produtor rural (ex.: análises laboratoriais) ou são incorporadas à atividade produtiva (ex.: envase do leite).

Diversos são os termos empregados para caracterização de setores econômicos que operam "fora das condições econômicas desejadas". Muitos trabalhos utilizam as nomenclaturas: mercado clandestino, mercado negro, informal, entre outros. Diante de todas essas denominações é necessária a unificação conceitual para a caracterização destes setores da economia, que se diferenciam principalmente em função do tipo de regra transgredida.

Para fins de conceituação, Feige (1990); Bánkut (2005) apresentam economia informal como atividades econômicas que estão às margens dos custos incidentes nos mercados formais e excluídas dos benefícios e direitos incorporados nas leis e nas regras administrativas tais como: direito de propriedade, licenças comerciais, contratos de trabalho, financiamento de crédito e dos direitos sociais. 
Trata-se, portanto, de qualquer atividade econômica que opera com regras próprias, ou seja, sem a obediência às regras formais do ambiente institucional ao qual opera. Entre os possíveis exemplos estão os produtores de leite e queijo que comercializam produtos sem cumprimento de regras sanitárias, fiscais etc. diretamente para consumidores finais e/ou pequeno varejo.

De acordo com Feige (1990), a diferença entre as economias formais e informais está no grau de aderência às regras institucionais, o descumprimento desta pode variar em função de cada setor, produto, mercado etc. Grande parte das economias informais compartilha da evasão fiscal enquanto outras da não obediência às leis trabalhistas, licenças para funcionamento, normas de inspeção sanitária etc. ou do conjunto destas (BANKUTI, 2005).

\section{MÉTODOS}

Esta pesquisa foi desenvolvida no Município de Itaqui, utilizando como proposta metodológica o Estudo de Caso, com o objetivo de obter informações atualizadas da forma com que os produtores informais de leite produzem e comercializam o produto no município. Fatores acerca de produção e produtividade também foram abordados.

O município de Itaqui em 2010 possuía uma população de 38.159 habitantes sendo que, desse total, 33.314 pessoas residem na zona urbana, e 4.848 habitam a zona rural (IBGE, 2012). Com uma área de $3.404,037 \mathrm{~km}^{2}$, está localizado na fronteira oeste do Rio Grande do sul, distante $760 \mathrm{~km}$ da capital Porto Alegre. Limitando-se a oeste com a República Argentina, ao leste com Maçambará, ao sul com Alegrete, Uruguaiana e Manoel Viana e ao norte com São Borja (IBGE, 2012).

A economia do Município de Itaqui está apoiada na rizicultura e pecuária, em que cerca de $80 \%$ do território destina-se a áreas agrícolas. Os outros $20 \%$ são ocupados pela pecuária e outras culturas como o cultivo de soja, trigo (IBGE, 2012). Primeiramente, a pecuária foi uma atividade preponderante no município e, com o passar do tempo, o arroz começou a predominar como atividade agrícola, até o município atingir o posto de segundo maior produtor estadual e estar entre os dez maiores produtores nacionais (IBGE, 2012).

Diante desse contexto, a presente pesquisa é composta de duas fases distintas:

1- Uma fase inicial de aprofundamento teórico, através de pesquisa bibliográfica sobre a cadeia produtiva do leite, bem como a informalidade do setor. As informações foram coletadas juntamente com os integrantes da equipe do projeto de Pesquisa Análise da Cadeia Produtiva do Leite na Fronteira Oeste: um estudo de caso no município de Itaqui/RS, com base em artigos científicos, monografias e teses relacionadas ao assunto, bem como no levantamento de dados estatísticos da realidade do município de Itaqui em institutos de pesquisas.

2- Em um segundo momento foram feitas entrevistas com aplicação de um questionário, que possibilitou a análise sob diversos ângulos e com mais profundidade no assunto. $O$ instrumento de pesquisa utilizado foi um roteiro semiestruturado, pois as perguntas foram previamente formuladas, permitindo que 0 entrevistado discorresse livremente sobre cada tema abordado.

Para compor os dados da pesquisa, também se realizou uma reunião com EMATER/RS - ASCAR localizadas no município de Itaqui, na qual se encontravam presentes os representantes do escritório municipal de Itaqui RS (Engenheiro Agrônomo e Assistente social), bem como, a Gerente Regional e os participantes da equipe do projeto de pesquisa. Por meio desta reunião foram relatadas experiências vividas pelos integrantes da instituição EMATER/RS, informações sobre outras 
regiões do estado e a realidade do município em relação à cadeia produtiva do leite. Além disso, também se realizou o planejamento para pesquisa a campo (mapeamento da localização dos produtores do município e número de produtores).

Segundo dados da inspetoria veterinária, o município possui 53 produtores de leite cadastrados. Destes, foram entrevistados somente os produtores de leite que atuam na área da informalidade, correspondendo a 20 produtores, dos quais se buscou características gerais da produção leiteira em suas propriedades. As entrevistas foram realizadas no período dos dias 2 a 10 de setembro de 2013, com produtores que trabalham com produção leiteira informal pertencente ao município de Itaqui.

O questionário utilizado para levantamento de dados empíricos contemplou os seguintes temas:

1) Aspectos Demográficos: Análise da idade e o grau de escolaridade do produtor;

2) Aspectos da Propriedade Rural: Tamanho da propriedade rural, localização, número médio de vacas leiteiras e produtividade do rebanho;

3) Produção Leiteira: Quantidade produzida para o mercado informal, preço alcançado por esses produtores;

4) Acesso ao Crédito: Crédito obtido pelos produtores informais, destino dos recursos do crédito;

5) Acesso a Assistência Técnica: Frequência da assistência técnica e púbica ou privada;

6) Canais de Comercialização: Os canais de comercialização utilizados por esses produtores, motivos que levaram os produtores a utilizarem cada canal e relacionamento do produtor com o consumidor.

No que se refere a análise qualitativa dos dados, destaca-se que os mesmos foram organizados buscando contestar o conjunto de variáveis elencado anteriormente, de forma que possibilitem uma análise em profundidade da realidade empírica, aliando a proposta teórica utilizada como suporte. Esta teoria busca constituir uma diferenciação no setor econômico empregado pelos produtores que operam na informalidade.

\section{RESULTADO E DISCUSSÃO}

Esta sessão visa apresentar os principais resultados da pesquisa, bem como discuti-los tendo por base o referencial teórico descrito. Destaca-se, inicialmente, que dos vinte produtores abordados, somente quinze deles responderam a entrevista. Dos cinco não respondentes, dois se opuseram a participar da pesquisa e três já haviam encerrado com as atividades relacionadas à produção leiteira.

Os três produtores que optaram pelo encerramento das suas atividades afirmam que esta decisão se deu devido à exigência pelo órgão de fiscalização sanitária de retirada dos animais do perímetro urbano (local onde se encontravam as propriedades); o elevado custo para produção leiteira (gastos com insumos); e a baixa remuneração pela venda do produto, sendo a relação custo/benefício inviável segundo esses produtores.

A seguir, portanto, são apresentados os dados dos produtores que se dispuseram a colaborar com a pesquisa. Primeiramente, os dados socioeconômicos e, a seguir, os dados dos estabelecimentos e aspectos técnicos - produtivos. Por fim, os aspectos verificados à campo são analisados a luz das teorias utilizadas. 


\subsection{Caracterização socioeconômica e aspectos técnico - produtivos}

A média de idade dos produtores informais pesquisados foi de 49 anos, sendo a idade mínima de 19 anos e idade máxima de 64 anos. Todavia, verifica-se que a maior parte dos sujeitos pesquisados encontra-se na faixa de 50 até 64 anos.

Conforme as observações realizadas no momento da pesquisa, pode-se afirmar que, no caso dos sujeitos entrevistados, a idade reflete sua experiência na atividade leiteira e sua dificuldade de lidar com novas tecnologias e compreender novas exigências de mercado. Se por um lado uma idade mais elevada demonstra grande experiência, por outro, implica maior dificuldade para o rompimento de aspectos culturais que, neste caso, observou-se estarem estritamente vinculados as "tradições familiares". Constatou-se ainda que os atuais agricultores já visualizaram o município de Itaqui como uma grande bacia leiteira, sendo o tradicionalismo que mantém produtores mais antigos nesta atividade. No que se refere às práticas e sistemas produtivos, essa atividade é passada de "pai para filho", conservando suas práticas de manejo para a produção de leite e limitando a modernização do seu sistema de produção.

Outro levantamento realizado diz respeito à escolaridade, a qual está relacionada ao acesso ao conhecimento e à possibilidade de adequação às mudanças tecnológicas. Dos 15 entrevistados, todos tiveram acesso à escola, embora a maioria restrito ao ensino fundamental (11 produtores) e ensino médio (4 produtores). Nenhum dos entrevistados possui ensino superior.

A área destinada para a atividade leiteira esteve entre os itens de investigação. Os resultados encontrados demonstraram que a maioria das áreas destinadas à exploração leiteira são cedidas pela prefeitura ou locais privados em desuso pelo proprietário. Assim, mais de $60 \%$ dos entrevistados habita e realizada a ordenha num espaço urbano de até $300 \mathrm{~m}^{2}$. Para o pastejo e descanso dos animais são utilizadas outras áreas periurbanas, via de regra de terceiros.

Os que possuem estabelecimentos próprios representam 6 sujeitos entrevistados. Entre estes, dois deles estão em condomínio familiar (com 2 ha e 12 ha respectivamente), o restante dispõem de uma área média de 3 ha. Portanto, são áreas pequenas/restritas de terra, dificultando a formalização, a qual exigiria produção em maior escala e tecnificação para ser rentável. Isso porque, em geral, as empresas de laticínios remuneram e precificam por quantidade, sendo que abaixo de certa quantidade torna-se economicamente inviável.

Essa afirmação se dá com base em um estudo de Bánkuti (2005) no qual o mesmo afirma que a área é fator indicativo da possibilidade de mudança de atividade nas propriedades rurais, pois áreas de tamanho muito reduzido podem limitar a atuação do produtor, restringindo a possibilidade de migração entre atividades. Além disso, Bánkuti (2005) assevera que áreas muito pequenas podem resultar na limitação do número de animais e na impossibilidade de atingir níveis de produção (em termos de volume) satisfatórios para terem acesso ao mercado formal.

Em relação ao número de vacas do rebanho, constatou-se heterogeneidade entre os produtores. Alguns têm um rebanho de apenas quatro animais e outros chegam a conter um rebanho leiteiro composto de 58 vacas. Por outro lado, o número de animais em lactação é em média quatro animais.

Conforme demonstra a Tabela 1 verifica-se uma variação na produtividade entre os diferentes produtores. Pelo contexto observado, mesmo as maiores produtividades, ainda são baixas comparativamente ao potencial que os animais de genética apropriada possuem para produção. Essa baixa produtividade, nos casos analisados, se deve a obsoleta tecnologia empregada, raças inapropriadas para 
produção de leite e a não adoção do melhoramento genético como prática das propriedades, área rural restrita para a produção de leite e, consequentemente, produção limitada de alimentos para os animais.

Tabela 1 - Produtividade Diária de leite

\begin{tabular}{c|cc}
\hline $\begin{array}{c}\text { Número de } \\
\text { Produtores }\end{array}$ & $\begin{array}{c}\text { Produção diária (L } \\
\text { de leite/vaca) }\end{array}$ & Porcentagem (\%) \\
\hline 3 & 15 a 11 & 20 \\
5 & 10 a 6 & 33,3 \\
6 & 5 a 2 & 40 \\
\hline 1 & OMITIU & 6,6 \\
\hline
\end{tabular}

Um fator importante para produtividade do rebanho é com relação ao perfil racial. Constatou-se que todos os entrevistados possuem um rebanho composto por animais de raças mistas (Gir x Holandesa; Holandesa x Jersey), ou seja, os rebanhos não apresentam uma uniformidade de raças, poucos deles possuem animais de alta qualidade genética voltada para a produção leiteira. Essa falta de melhoramento genético reflete na baixa produtividade dos animais, em que a maioria das propriedades (11) não ultrapassa $10 \mathrm{l} / \mathrm{vaca} / \mathrm{dia}$.

Dentre os gargalos identificados como prejudiciais à produção de leite nos estabelecimentos analisados, destaca-se a localização destes, pois onze das quinze propriedades analisadas possuem sua produção leiteira em áreas urbanas, dificultando o manejo com os animais, bem como a expansão da atividade. Outro fator limitante é a exigência da prefeitura de retirada destes animais do território urbano. Somente quatro propriedades se localizam na área rural do município.

Em relação ao acesso ao crédito, constatou-se que $100 \%$ dos produtores mencionaram nunca ter tido acesso a nenhum tipo de crédito. Ao serem questionados sobre o motivo que os levaram a não demandar crédito, declararam: a) medo de adquirir dívida; b) muitas exigências na hora da aquisição; c) não achar necessária a obtenção de créditos.

Assim como o acesso ao crédito, nenhum dos entrevistados declarou receber a assistência técnica, exceto da inspetoria veterinária com a vacina da aftosa. Quando interrogados em relação a casos de doença no rebanho e a necessidade de utilização de um tipo medicamento, declararam que, por experiência própria na produção leiteira, eles mesmos identificavam a doença e automedicam o seu rebanho. Mesmo assim, mostraram-se insatisfeitos com órgãos públicos pela falta de atenção e assistência a esse tipo de produtores.

\subsection{Canal de comercialização}

No que se refere às formas de comercialização e formação de preço, destaca-se que o único canal de comercialização encontrado entre os entrevistados foi "a venda diretamente para o consumidor final", ou seja, a entrega do leite de "porta em porta". São clientes certos onde a entrega do leite é diária e o pagamento é baseado na confiança e feito por mês.

Além disso, para a totalidade dos entrevistados, o preço é um grande atrativo de comercialização informal. $O$ valor por litro de leite alcançado no mercado informal foi uma das principais justificativas mencionadas pelos entrevistados por estarem na informalidade. Segundo os produtores, o preço pago pela venda do leito informal é três vezes maior do que o pago pela empresa coletora. Segundo os 
sujeitos pesquisados, o valor obtido pelos produtores foi em média de $R \$ 1,59$ por litro de leite contra $R \$ 0,60$ a $R \$ 0,40$ centavos oferecido pela empresa compradora, segundo entrevistados.

Destaca-se que os valores verificados pela pesquisa são coerentes com as características da região que, conforme Breitenbach (2012) caracteriza-se por monopsônio concorrencial. Segundo a autora, na região apenas uma empresa interessava-se em adquirir o leite dos agricultores desse município. Essa estrutura de mercado de fatores, com baixa rivalidade entre empresas, trouxe como consequência redução do poder desses agricultores em detrimento do poder da empresa processadora, com expressiva redução do preço pago pelo leite, se comparado com regiões em que existia maior concorrência. Além disso, a pesquisa de Breitenbach (2012) demonstrou que a quantidade comercializada era o principal fator determinante do preço pago ao produtor, sendo esse mais um indicativo para o baixo preço que os agricultores receberiam caso comercializassem para empresas processadoras, já que produzem em pequena quantidade.

Cerca de 11 produtores vendem seu produto ao preço de $R \$ 1,50$ litro do leite e apenas três obtém um preço mais elevado ( $R \$ 2,00$ litro do leite). O menor valor pago encontrado entre eles foi de $R \$ 1,25$, em que o produtor justificou que se ele aumentasse o preço não teria freguesia. Mesmo assim, a maioria dos entrevistados mostrou-se satisfeito com o valor recebido, bem como destacam um aumento de demanda pelo produto deles após os reconhecidos escândalos de fraude no leite formal e, consequentemente, teve um aumento do preço pago a eles.

Conforme verificado na pesquisa, a escolha do canal de comercialização se deu com base em alguns fatores, os quais estão elencados por ordem de importância no Quadro 1.

\section{Quadro 1 - Condicionantes da escolha do canal de comercialização pelos agricultores} entrevistados.

\begin{tabular}{|c|c|}
\hline \multirow{3}{*}{ 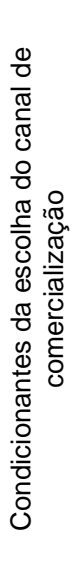 } & $\begin{array}{l}\left.1^{\circ}\right) \text { Preço: Ficou claro que o principal motivo de utilização deste } \\
\text { canal de comercialização é o preço pago na venda direta. Dos } \\
\text { entrevistados, } 100 \% \text { mencionou que o preço pago direto pelo } \\
\text { consumidor é três vezes maior que o pago pela empresa } \\
\text { coletora. }\end{array}$ \\
\hline & $\begin{array}{l}2^{\circ} \text { ) Confiança no recebimento/ relacionamento: Existe um acordo } \\
\text { entre produtor e consumidor em que as entregas do leite são } \\
\text { feitas diariamente e o pagamento é feito por mês, obtendo assim } \\
\text { um bom relacionamento entre comprador e vendedor. Apesar } \\
\text { disso, quatro dos sujeitos entrevistados destacaram que as } \\
\text { vezes há falta de pagamento em alguns meses, mesmo assim } \\
\text { mostram-se satisfeitos com a forma de escoamento de sua } \\
\text { produção. }\end{array}$ \\
\hline & $\begin{array}{l}\left.3^{\circ}\right) \text { Facilidade de escoamento: Devido a alta perecibilidade do } \\
\text { leite e a falta de local para armazenamento, os produtores obtém } \\
\text { sua produção diária conforme a quantidade de escoamento do } \\
\text { dia, facilitando o escoamento para que não haja perda de } \\
\text { produto. }\end{array}$ \\
\hline
\end{tabular}

Tendo por base o levantamento de informações empíricas, foi possível caracterizar os produtores informais de leite do município de Itaqui. Essa diferenciação foi construída através da classificação feita pelos autores Feige (1990), Ritter (2004), Azevedo e Bánkuti (2002), conforme esquematiza o Quadro 2. 
Quadro 2 - Caracterização dos setores econômicos

\begin{tabular}{|c|c|c|c|}
\hline Autor & $\begin{array}{c}\text { Tipo } \\
\text { Ativida- } \\
\text { des }\end{array}$ & $\begin{array}{c}\text { Características Gerais } \\
\text { das Atividades }\end{array}$ & $\begin{array}{c}\text { Realidade Empírica } \\
\text { Verificada }\end{array}$ \\
\hline $\begin{array}{l}\text { Feige } \\
(1990)\end{array}$ & $\begin{array}{l}\text { Econo- } \\
\text { mia } \\
\text { Informal }\end{array}$ & $\begin{array}{l}\text { Atividades que operam } \\
\text { às margens dos custos } \\
\text { impostos aos mercados } \\
\text { formais e não partilham } \\
\text { dos direitos legais } \\
\text { (direito de propriedade, } \\
\text { seguro social etc). }\end{array}$ & $\begin{array}{c}\text { Produção e } \\
\text { comercialização sem } \\
\text { qualquer registro e } \\
\text { inspeção sanitária, } \\
\text { todavia as matrizes } \\
\text { leiteira são registradas } \\
\text { na inspetoria } \\
\text { veterinária. }\end{array}$ \\
\hline $\begin{array}{l}\text { Ritter } \\
(2004)\end{array}$ & $\begin{array}{l}\text { Econo- } \\
\text { mia } \\
\text { Informal }\end{array}$ & $\begin{array}{l}\text { Atividades que operam } \\
\text { fora do aparato fiscal e } \\
\text { regulatório dos órgãos } \\
\text { oficiais. }\end{array}$ & $\begin{array}{l}\text { Desenvolvem uma } \\
\text { atividade sem } \\
\text { regulamento fiscal, } \\
\text { todavia cerca de } 53 \% \\
\text { dos proprietários } \\
\text { entrevistados } \\
\text { possuem Bloco de } \\
\text { produtor } \\
\end{array}$ \\
\hline $\begin{array}{l}\text { Azevedo } \\
\text { e Bánkuti } \\
\text { (2002) }\end{array}$ & $\begin{array}{l}\text { Mercado } \\
\text { paralelo } \\
\text { com } \\
\text { produtos } \\
\text { heterogên } \\
\text { eos }\end{array}$ & $\begin{array}{l}\text { Consumidores } \\
\text { distinguem produtos } \\
\text { informais dos formais. } \\
\text { Optam pela melhor } \\
\text { relação custo benefício. }\end{array}$ & $\begin{array}{c}\text { Comercialização pelo } \\
\text { melhor custo e } \\
\text { benefício; Venda } \\
\text { direta ao consumidor; } \\
\text { sem qualquer } \\
\text { inspeção sanitária e } \\
\text { controle de qualidade } \\
\text { do produto. } \\
\end{array}$ \\
\hline
\end{tabular}

Entre os conceitos utilizados pelos autores o que mais condiz com a realidade encontrada entre os produtores informais de Itaqui é o dos autores Azevedo e Bánkuti, conforme observado no Quadro 2. O que permite classificá-los como tal é o fato desses produtores operarem em uma atividade econômica em que o principal objetivo é o lucro, além da utilização do canal de comercialização (venda direta ao consumidor). Todas as atividades desenvolvidas pelos produtores são feitas sem qualquer inspeção sanitária e nenhum tipo de controle de qualidade do produto. A fim de reiterar as informações, conforme a lei, o comércio de leite cru é proibido no Brasil desde a década de 1950 pela Lei no 1.283 , de 18/12/1950, e pelo Decreto $n^{\circ}$ 30.691, de 29/03/1952 (BRASIL, 1997).

\subsection{A informalidade, a fraude e o consumo de leite}

Observa-se como resultados da pesquisa uma reação importante dos consumidores locais da cidade a partir do cenário recente das frequentes fraudes identificadas no mercado de lácteos. Essa reação se concentrou na aparente mudança na característica do consumo destes, percebida a partir da pesquisa junto aos produtores rurais.

Primeiramente, ficou evidente em suas colocações o acréscimo na demanda pelo leite informal produzido por eles. Dessa forma, considera-se um resultado importante e surpreendente ao passo que se identifica que parte da população local opta por passar a consumir um leite não inspecionado e, muitas vezes, produzido fora dos padrões sanitários legais, que não paga impostos, em 
detrimento de consumir/comprar de empresas que pertencem a cadeias produtivas formais e consolidadas.

Acrescenta-se a esse fator, a descrença da população acerca dos Serviços de Inspeção. Ao optarem pelo mercado informal as pessoas demonstram que podem não acreditar no rigor da fiscalização e na qualidade atestada aos produtos que compram e consomem no mercado formal. Somado a isso, existe a parcela da população que correlaciona o informal com o caseiro, local e, portanto, de boa procedência e confiável. Fatores estes que, individualmente ou em conjunto, favorecem a demanda pelos produtos do mercado informal. O descrédito verificado no mercado formal, ocasionado pelas recentes e sucessivas descobertas de fraudes no mercado formal de leite, corrobora para a confirmação da hipótese lançada anteriormente que aponta o aumento na demanda de leite informal após as denúncias.

Portanto, esse dado deixa clara a insegurança que as fraudes criaram nos consumidores do local analisado, se refletindo em redução de confiabilidade do mercado formal e aumento de demanda no mercado informal. Esse fator prejudicou os consumidores, mas beneficiou os produtores informais.

Esse benefício para os agricultores se concentrou, especificamente, no aumento do preço do leite baseado na principal regra de mercado que segue a relação entre oferta e demanda. Ou seja, aumentou a demanda pelo produto e, consequentemente, aumentou o preço do mesmo. Para esses agricultores é visível a vantagem, já que com a mesma quantidade de produto conseguem uma rentabilidade maior.

Por outro lado, demonstra as fragilidades do setor, que foi abalado pelas fraudes. Para esclarecer, essas fraudes se tratam de descobertas de adulterações no leite, no qual o Ministério Público brasileiro identificou a presença, especialmente, de álcool, soda e formol no produto final de importantes marcas nacionais. Agentes estes que são cancerígenos e extremamente proibidos por lei. Em sua maioria são utilizados para mascarar problemas de contaminação bacteriana e/ou para aumentar as quantidades do produto a partir da colocação de água, sendo os produtos utilizados para que a adulteração não seja identificada nos testes de qualidade.

\section{CONSIDERAÇÕES FINAIS}

De acordo com as análises apresentadas, os produtores informais do município de Itaqui/RS, analisados nesta pesquisa, são "reféns" do mercado informal em função de suas características econômicas e sociais. Conforme observado, mesmo com bastante experiência na atividade leiteira, constatou-se que os produtores demonstram como estratégia de sobrevivência para sua realidade particular, qual seja de pouca disponibilidade de áreas e baixa escala produtiva, a não adequação a novas tecnologias e aos aspectos normativos.

Somasse-se a isso o fato de que esses agricultores identificaram no mercado informal um nicho de consumidores dispostos a adquirir o produto e a pagar mais do que as empresas processadoras da região. Portanto, esses agricultores familiares adotaram o mercado informal como uma estratégia de reprodução, sendo essa estratégia usada por eles há muitos anos e estando agora, devido a aspectos favoráveis de mercado, trazendo maiores retornos financeiros.Conclui-se que os produtores de leites de Itaqui enfrentam várias barreiras, entre elas pode-se destacar que a grande maioria trabalha com áreas cedidas pela prefeitura (áreas não próprias) ou locais privados em desuso pelo proprietário. Isso indica que esses produtores têm acesso a uma quantidade insatisfatória de terra dificultando o aumento da escala de produção, bem como 
investimentos futuros na atividade. Além disso, os rebanhos não apresentam uma uniformidade de raças, poucos deles possuem animais de alta qualidade genética voltada para a produção leiteira. Entre as dificuldades enfrentadas pelos produtores, destaca-se também a localização das propriedades, pois a maioria dos entrevistados possui sua produção leiteira em área urbana, dificultando o manejo dos animais, além de impedir um possível aumento na produção.

Entretanto, existem outras razões que incentivam a permanência desses agricultores na atividade e, em especial, para preferência deste canal de comercialização: a informalidade. Dentre elas destaca-se a razão econômica, pois consideram o produto melhor remunerado no mercado informal e com demanda e preço em expansão após fraudes recorrentes no leite formal. Ou seja, a atividade de bovinocultura de leite tem se tornado, ao longo dos anos, uma atividade exigente em tecnologia, mão de obra e investimentos em geral. Além disso, sendo a quantidade produzida um dos principais fatores determinantes do preço (especialmente em Alegrete), a escala produtiva combinada a estratégia de redução de custos tem sido determinante para a rentabilidade e lucratividade do setor. Dessa forma, propriedades rurais com escassos recursos, como é o caso das analisadas nessa pesquisa, carecem de estratégias de diferenciação. Tendo por base esse raciocínio, verifica-se que as propriedades analisadas optaram pela diferenciação comercial, especialmente por identificar a existência de um mercado para a venda informal do produto com remuneração significativamente superior.

Por fim, alerta-se que existem riscos nesse tipo de comercialização. Esses riscos são tanto para quem comercializa, quanto para quem compra o produto. Para os agricultores, os riscos se concentram nas penalidades legais da venda informal, enquanto que para os consumidores os riscos residem em adquirir um produto sem fiscalização e sem controle de qualidade.

\section{REFERÊNCIAS BIBLIOGRÁFICAS}

AZEVEDO, P. F.; BÁNKUTI, F. I. When food concern decreases safety: evidences from the meat informal market. International Society for New Institucional Economics 6 th. Annual meeting. Institutions and and Economic performance. Cambrigde, 2002.

BADINI, K. B.; NADER, FILHO, A.; AMARAL, L. A. Hábitos dos consumidores de leite cru, produzido e comercializado clandestinamente nos municípios de Botucatu/ SP e de São Manuel/SP. Revista Higiene Alimentar, v. 11, n. 51. p.15-17, 1997.

BÁNKUTI, F. I.; SCHIAVI, S. M. A.; SOUZA FILHO, H. M. Quem são os produtores de leite que vendem em mercados informais? XLIII Congresso da Sociedade Brasileira de Economia e Sociologia Rural - SOBER. Instituições, Eficiência, Gestão e Contratos no Sistema Agroindustrial. Ribeirão Preto, SP. Julho, 2005.

BÁNKUTI, F. I. Entraves e incentivos ao abate clandestino de bovinos no Brasil. 2002. 159 f. Dissertação (Mestrado em Engenharia de Produção) - Universidade Federal de São Carlos, São Carlos, 2002.

BÁNKUTI, F. I. Entraves para inserção de produtores de leite no mercado formal da região de São Carlos, estado de São Paulo. 2005. Disponível em:< http://gadoleiteiro.iepec.com/noticia/entraves-para-insercao-de-produtores-nomercado-formal-da-regiao-de-sao-carlos->. Acesso em 22 outubro de 2013. 
BÁNKUTI, F. I. Incentivos à informalidade no sistema agroindustrial do leite. 2009. Artigo. Disponível em: http://gadoleiteiro.iepec.com/noticia/incentivos-ainformalidade-no-sistema-agroindustrial-do-leite- Acesso em: 11 ago de 2013.

BARBOSA, P. F. Produção de Leite no Sudeste do Brasil. EMBRAPA Gado de Leite. 2003. Juiz de Fora, Minas Gerais. Informações técnicas - Sistema de Produção 4. Disponível em: http://www.cnpgl.embrapa.br/. Acesso em: 6 Ago. 2013.

BRASIL. Ministério da Agricultura Pecuária e Abastecimento. Instrução Normativa no 51 de 2002. Diário Oficial da República Federativa do Brasil, Brasília, DF, 20 set. 2002.

BRASIL. Ministério da Agricultura, Pecuária e Abastecimento. Instrução Normativa N. 62 de 18 de setembro de 2004. Oficializa os Métodos Analíticos Oficiais para Análises Microbiológicas para Controle de Produtos de origem Animal e Água, 2003. Diário Oficial da união, Brasília, DF, 18 set. seção 1 p.14, 2004.

BRASIL. Ministério da Agricultura. Decreto n. 30.691, de 29 de março de 1952 , alterado pelos Decretos n's.1255, de 25 de junho de 1962, n. 1236, de 2 de setembro de 1994, n.1812, de 8 de fevereiro de 1996, e n. 2.244, de 4 de junho de 1997. Regulamento da Inspeção Industrial e Sanitária dos Produtos de Origem Animal - RIISPOA.

Brasília, DF, 1997.

BREITENBACH, R. Estrutura, conduta e governança na cadeia produtiva do leite: um estudo multicaso no Rio Grande do Sul. Tese (doutorado) - Universidade Federal de Santa Maria, Programa de Pós Graduação em Extensão Rural, RS, 2012.

CARVALHO, G. C. A indústria de laticínios no Brasil: passado, presente e futuro. EMBRAPA Gado de Leite. 2010. Juiz de Fora, Minas Gerais. Circular Técnica. Disponível em: http://www.cnpgl.embrapa.br/nova/livraria/abrir_pdf.php?id=26 . Acesso em: 6 ago. 2013.

CARVALHO, V. R. F. Reestruturação do sistema lácteo mundial: uma análise da inserção brasileira. Tese (Doutorado)-Universidade Estadual de Campinas, Instituto de Economia, Campinas, 2008.

EMBRAPA GADO DE LEITE, 2012 EMBRAPA GADO DE LEITE. Estatísticas do Leite. Disponível em: www.cnpgl.embrapa.br. Acesso em: 11 de agosto de 2013.

EMPRESA BRASILEIRA DE PESQUISA AGROPECUÁRIA. Circular Técnica 104. O mercado lácteo brasileiro no contexto mundial, 2010 p1 a p12.

FAO - FOOD AND AGRICULTURE ORGANIZATION. Homepage da FAO, 2010. Disponível em: <www.fao.org>. Acesso em: 6 ago. 2013.

FAOSTAT - Food and Agriculture Organization of the United Nations. Disponível em: <www.fao.org >. Acesso em: 18 out. 2013.

FARINA, E. M. M. Q. Leite clandestino: um problema real. Boletim do Leite, São Paulo, v. 7, n. 81, p. 1-2, 2000. 
FEIGE, E.L. Defining and Estimating Underground and Informal Economies: The New Institutional Economics Approach. World Development. Vol. 18, n. 7. 1990.

GERMANO, M. I. S. Treinamento de manipuladores de alimentos: fator de segurança alimentar e promoção de saúde. São Paulo: Varela: Revista Higiene Alimentar, p-165, 2003.

GOMES, S.T. Cadeia produtiva do leite - parte 3. Disponível em: <www.milkpoint.com.br/mn/utils>. 03/08/2000. Acesso em: 10 ago. 2013.

Guerra, J. Instrução normativa no 51 e no 62, o que muda? Scot, 2 mar. 2012. Seção de artigos. Disponível em: <http://scotconsultoria.com.br/ noticias/artigos/22793/skype:scot consultoria>. Acesso em: 9 ago. 2013.

IBGE - Instituto Brasileiro de Geografia e Estatística. 2010. Pesquisa da Pecuária Municipal. Disponível em <www.sidra.ibge.gov.br>. Acesso em: 18 out. 2013.

IBGE. Instituto Brasileiro de Geografia e Estatística. Notícias. 2012. Disponível em: <http://www.ibge.gov.br/home/>. Acesso em: 6 Ago. 2013.

WILKINSON, J.; MIOR, L. C.. Setor informal, produção familiar e pequena agroindústria: interfaces. Estudos Sociedade e Agricultura, Rio de Janeiro, n. 13, p.29-45, 1999.

LEITE, J. L. B. Comércio internacional de lácteos. Juiz de fora: Templo, 2008.

MAIA G, B. S.; PINTO, R. A.; MARQUES, Y. T. ; ROITMAN, F. B. ; LYRA, D. D. Produção leiteira no Brasil. 2013. Disponível: $<$ http://www.bndes.gov.br/SiteBNDES/export/sites/default/bndes_pt/Galerias/Arquivo s/conhecimento/bnset/set3709.pdf > Acesso em: 10 ago.2013.

NERO, L. A.; MAZIERO, D.; BEZERRA, M. M. S. Hábitos alimentares do consumidor de leite cru de Campo Mourão, PR. Seminário: Ciências Agrárias, v. 24, n. 1, p. 21 26, 2003.

OLIVAL, A. de A.; SPEXOTO, A. A. Leite informal no Brasil: aspectos sanitários e educativos. Revista Higiene Alimentar, v. 18, n. 119. p. 12-17, abr. 2004.

PERIN, O. R.; FERREIRA, G.M.V.; TALAMINI, E. Percepção de qualidade no processo produtivo do leite: um estudo de caso no Rio Grande do Sul. Organizações Rurais \& Agroindustriais, vol. 11, núm. 3, septiembre-diciembre, 2009, pp. 436-451, Universidade Federal de Lavras.

PINHA, L. C.; TRAVASSOS, G. F.; CARVALHO, G. R. O consumo do brasileiro no pós-crise. Boletim CBLeite, Juiz de Fora, v. 4, n. 12, p. 49-51, dez. 2010.

PORTZ, A. J. Avaliação da presença de resíduos de antibióticos e da qualidade microbiológica em leites cru e beneficiado no Distrito Federal. Monografia 
Faculdade de Agronomia e Medicina Veterinária da Universidade de Brasília. 2011. Disponível:http://bdm.bce.unb.br/bitstream/10483/3057/1/2011_AnnaJuliaPortz.pdf

RITTER, A.R.M. Cuba's Underground Economy. Economics and International Affairs, Carleton University. Canada, 2004.

SANTINI, G. A.; PEDRA, D. F. B. M.; PIGATTO, G. Internacionalização do setor lácteo: a busca pela consolidação. In: SOCIEDADE BRASILEIRA DE ECONOMIA ADMINISTRAÇÃO E SOCIOLOGIA RURAL. 47. , 2009, Porto Alegre. Anais. Porto Alegre, 2009.

SANTOS, G.T.; DAMASCENO, J.C.; MASSUDA, E.M.; CAVALIERI, F.L.B. Importância do Manejo e Considerações Econômicas na Criação de Bezerras e Novilhas. Anais do II Sul- Leite: Simpósio sobre Sustentabilidade da Pecuária Leiteira na Região Sul do Brasil. Maringá : UEM/CCA/DZO - NUPEL, 2002. 212P. Toledo - PR, 29 e 30/08/2002. Págs. 239-267. 2002.

SANTOS, M. V.; FONSECA, L. F. L. Características de composição do leite e métodos de análise $-2^{\circ}$ Curso on line sobre a qualidade do leite. Disponível em: <http://www.milkpoint.com.br/mn/cursosonline>. 01 maio 2002. Acesso em: 02 ago de 2013.

SANTOS, O. V.; MARCONDES, T. ; CORDEIRO, J. L. F. Estudo da cadeia do leite em Santa Catarina; prospecção e demandas. (Versão preliminar). Florianópolis: Epagri/Cepa, $2006 . \quad$ Disponível em: <http://cepa.epagri.sc.gov.br/Publicacoes/Estudo\%20da\%20Cadeia\%20do\%20leite.p df >. Acesso em: 12 ago de 2013.

SANTUCCI, J. O leite nosso de cada dia. Revista Bimestral do Conselho Regional de Engenharia e Agronomia do Rio Grande do Sul: v. 9, n.97. p.17-21, jul/ago 2013.

SCACO, A. R. Proposição de um modelo de referência para gestão da qualidade na cadeia de produção de leite e derivados. São Carlos, 2005. 225 f. Tese (Doutorado) - Universidade de São Carlos.

SCOT CONSULTORIA. 2010.2 Disponível em: $<$ https://www.scotconsultoria.com.br/leite/balanca-comercial/81/aumentaram-asimportacoes-de-soro-de-leite-em-2010.htm>. Acesso em: 30 setembro de 2013

SILVA, N. ; JUNQUEIRA, V. C. A. ; SILVEIRA, N. R. A. Manual de métodos de analise microbiológica da água. São Paulo: Varela, 317p. 2000.

SIMÕES, A. R. P.; OLIVEIRA, M. V. M. Vantagens comparativas do Brasil na produção de leite. In: Congresso Brasileiro Economia e Sociologia Rural, 43, 2010. Campo Grande. Anais... Campo grande: UFMS, 2010. 1 CED-ROm. 2010.

SINDILAT/RS Sindicato da Indústria de Laticínios e Produtos Derivados do Estado do Rio Grande do Sul, 2012. Disponível em: <http://www.sindilat.com.br/> Acesso em 14 agosto de 2013. 
VILELA, D.; LEITE, J. L. B.; RESENDE, J. C. Políticas para o leite no Brasil: passado presente e futuro. In: Santos, G. T.; Jobim, C. C.; Damasceno, J. C. Sul-Leite Simpósio sobre Sustentabilidade da Pecuária Leiteira na Região Sul do Brasil, 2002, Maringá. Anais... Maringá: UEM/CCA/DZONUPEL, 2002.

ZANELA, M.B.; RIBEIRO, M.E.R.; FISCHER, V. Ocorrência do leite instável não ácido no noroeste do Rio Grande do Sul. Arquivo Brasileiro de Medicina Veterinária e Zootecnia, v.61, p.1009-1013, 2009. 